\title{
Proximate effects of maternal oviposition preferences on defence efficacy and larval survival in a diet-specialised tortoise beetle. Who knows best: mothers or their progeny?
}

\author{
FREDRIC V. VENCL, ${ }^{1,2}$ C A M I L A A. PLATA C ${ }^{3}$ and \\ R O B E R T B. S R Y G L E Y ${ }^{2,4}{ }^{1}$ Ecology and Evolution, Stony Brook University, Stony Brook, New York, \\ U.S.A., ${ }^{2}$ The Smithsonian Tropical Research Institute, Balboa, Republic of Panamá, ${ }^{3}$ Centro de Investigaciones en Microbiología \\ y Parsitología Tropical, Universidad de los Andes, Bogotá, Colombia and ${ }^{4}$ USDA-Agricultural Research Service, Northern Plains \\ Agricultural Research Lab, Sidney, Montana, U.S.A.
}

Abstract. 1. The fate of an immature herbivorous insect depends on its mother's ability to locate a host that fosters optimal growth. However, immature performance and survival is often decoupled from female host preference.

2. We used defence manipulation and exclusion experiments to investigate how oviposition choices impact survival in the diet-specialised leaf beetle, Acromis sparsa, whose larvae are defended by host-derived chemical shields, gregariousness and maternal guarding, but can only migrate within a narrow range of leaf options upon the natal host.

3. Females preferred to oviposit on mature leaves of Merremia umbellate morning glory vines their sole host, that were high above ground where egg parasitism was least, although survival of fully defended larvae was greater on young leaves near to the ground.

4. Because ant attacks were prevalent in low sites, while bug and wasp attacks were frequent in high sites, we expected a relationship between sequesterable chemicals, defence efficacy and apparency to site-specific predators.

5. Shields were effective in low but not in high sites. Guarding was effective against ants and bugs in high, but not in low sites. Shields and gregariousness were effective against ants on mature leaves, but ineffective against bugs on young leaves.

6. Shields derived from young leaves, which were richer in oleic acid, were more effective against wasps then bugs. Larvae in high sites migrated to young leaves that contained less phytol, a bug attractant.

7. Larval migration may be an adaptation for the exploitation of enemy-free space when maternal oviposition choices are not optimal for survival.

Key words. Acromis sparsa, dietary specialisation, enemy-free space, maternal care, oleic acid, phytol.

\section{Introduction}

The fate of an herbivorous larval insect depends primarily on its mother's ability first to locate a suitable host plant, and then to lay her eggs on those host's tissues that best

Correspondence: Fredric V. Vencl, Ecology and Evolution, Stony Brook University, Stony Brook, New York 11794-5245, U.S.A. E-mail: fvencl@life.bio.sunysb.edu foster its growth and survival-the central prediction of the 'mother-knows-best' hypothesis (Jaenike, 1978; Valladares \& Lawton, 1991). As the majority of herbivorous insects are dietary specialists that can feed only on one or a few closely related host taxa, this makes oviposition decisions of paramount importance to fitness (Bernays \& Chapman, 1994). However, once an appropriate host is found, the impact of a mother's proximate, small-scale choices, can be confounded 
by the subsequent and numerous difficulties encountered by her larvae, especially if they, like the majority of Lepidoptera, sawflies and leaf beetles, feed openly upon leaf surfaces. Moreover, if they have little or no capacity to migrate to another host, these ectophytic larvae become more vulnerable to predators and parasitoids, which can reliably locate them and inflict mortality rates that often approach $90 \%$ (Zalucki et al., 2002). In response to such intense selection, ectophytic larvae have evolved a diversity of remarkable defensive traits, many of which rely on the sequestration of host plant metabolites, to thwart the depredations of their enemies (e.g. Nishida, 2002).

What has remained problematic in our understanding of the recurrent evolution of specialised diets in herbivorous insects is the fact that numerous studies have shown that female host choices do not often coincide with the selection of the best nutritional resources for the growth and development of their progeny (Thompson \& Pellmyr, 1991; Nylin \& Janz, 1993; Mayhew, 1997). In some of these cases, offspring performance is higher on hosts preferred by ovipositioning females (reviewed by Gripenberg et al., 2010), but many other studies report that female preference and larval performance are largely decoupled or weakly correlated, at best (Ballabeni et al., 2001; Moon \& Stirling, 2006; Clark et al., 2011). Moreover, a recent study indicates that oviposition completely off the host significantly reduces larval predation (De-Silva et al., 2011). Even the immatures of specialist herbivores still suffer significant mortality, despite their fine-tuned adaptations to tolerate their hosts' defences (e.g. Larsson \& Ohmart, 1988; Berenbaum \& Zangerl, 1998). What can explain the frequent disconnect between restricted host use and larval survival?

Traditionally, most studies exploring preferenceperformance decoupling have focused on measuring aspects of leaf quality (Kouki, 1993; Singer et al., 2004; Boege, 2005), or on the influence of host antiherbivore defences (Bjorkman et al., 1997; Coley et al., 2006; Pearse, 2011), even though natural enemies are well recognised to be important sources of mortality in many systems (e.g. Singer \& Stireman, 2005). Even for specialists, variation between site-dependent predation pressure and favourable host tissues for larval development likely represent conflicting selection pressures on female oviposition decisions (Awmack \& Leather, 2002; Bernays et al., 2004). However, with the exception of leaf miners (e.g. Larsson et al., 1997; Oppenheim \& Gould, 2002), there has been little research examining whether specialists can actively use plant architecture as sanctuary for their ectophytic progeny (e.g. Heisswolf et al., 2005). Moreover, the capacity of vulnerable immatures to mitigate their mother's decisions by migrating to more protected sites on the host (e.g. Larsson et al., 1997), or by seeking host tissues that may enhance their antipredator defences has not been adequately explored (e.g. Peñuelas et al., 2006).

Here, we examine whether the oviposition choices of the diet-specialised neotropical tortoise beetle, Acromis sparsa (Chrysomelidae: Cassidinae), affect the defence performance and survival of its ectophytic larvae. The larvae of A. sparsa feed exclusively on the leaves of the morning glory vine, Merremia umbellata (Convolvulaceae). The defence arsenal of A. sparsa consists of three components: (1) females, using

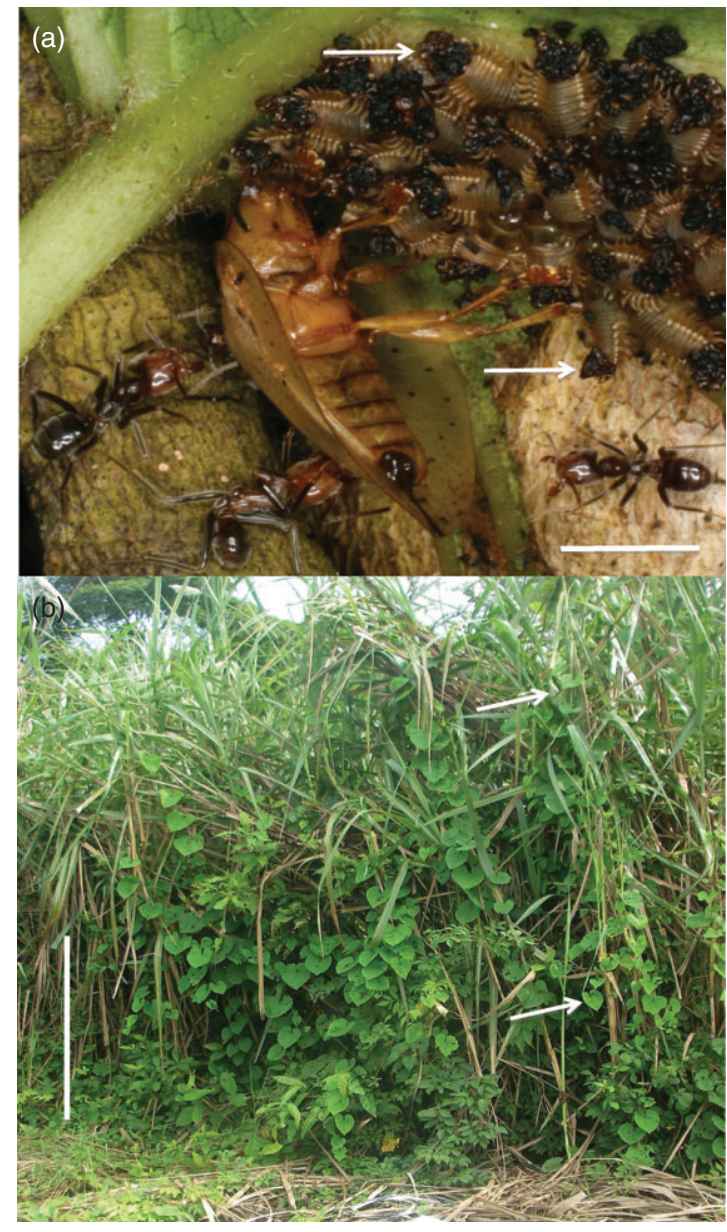

Fig. 1. The Merremia-Acromis system: (a) With her highly expanded elytra serving as a barrier, an Acromis sparsa female uses a ploughing manoeuvre to defend her third instar brood from Azteca lacrymosa ant attackers. The larvae have formed a tight rosette with their shields (arrows) oriented outward from the centre of the aggregation (scale $=3 \mathrm{~mm}$ ); and (b) using Saccharum sponteneum as a trellis, entwining Merremia umbellata vines provide gradients of insulation, exposure and leaf age (young leaf $=$ top arrow; low site $=$ bottom arrow; scale $=1 \mathrm{~m}$ ).

their broadly expanded elytra as a barrier, are noteworthy for their continuous guarding of progeny, from egg to adult emergence (Fig. 1a); (2) larvae are well known for a curious, but highly effective defence that resembles a shield (Fig. 1a). Formed by the accumulation of cast skins (exuvia) and retained faeces on a highly mobile caudal process, shields can be aimed with alacrity to block attackers. Applied with precision by a telescoping anus to the exuvia-covered caudal process, digestive wastes, fortified with modified host-derived metabolites, make shields a potent chemical defence (Vencl et al., 1999, 2005); and (3) when not feeding, larvae assemble into tightly knit rosettes, with their shields oriented outward to form a deterrent phalanx (Fig. 1a). Previous research demonstrated that particular larval defences target specific predator guilds. For instance, shields are particularly effective 
against ants, gregariousness reduces the impact of bugs, while maternal guarding functions well against wasps (Vencl \& Srygley, 2013). Phylogenetic ancestral state reconstructions revealed a sequence of trait accumulation, and suite assembly that resulted in a pattern consistent with the ideas of reciprocal coevolution and escalation (Thompson, 2005; Vencl et al., 2011; Vencl \& Srygley, 2013).

Given that they invest in a large egg mass, laid at a single location on one host species, in addition to the remarkable expense of guarding such a concentrated investment for the entire egg-to-adult developmental period, A. sparsa females confront many potential selective conflicts. For instance, if leaves differ in concentrations of sequesterable shield chemical precursors, as well as in their exposure, mothers would face a conflict between potentially diminished shield efficacy and apparency, even within a single host plant species. The outcomes of proximate oviposition choices likely represent directional trends that have driven the evolution of oviposition behaviour and of diet breadth itself. Moreover, it remains unknown if larvae are passive objects, or are able to mitigate the consequences of default maternal oviposition decisions.

Specifically, we quantify the influences of oviposition site and leaf age decisions made by females on larval survival against a diversity of predators in the field. As larvae have some capacity to migrate on the host, we further evaluate whether larvae can offset their mother's decisions by seeking more concealed feeding sites or feeding on leaves with higher levels of sequesterable, antipredator, defensive chemical precursors. Because its traits can be modified or ablated without otherwise harming individuals, the larval defence arsenal of $A$. sparsa represents a very tractable system with which to examine how oviposition site and leaf age choices affect defence performance against different enemies. Predator exclusion and defensive trait manipulation experiments were designed to render larvae either more or less defended, and the survival of individuals was quantified in a 4-year field study. Because plant architecture is thought to influence vulnerability to predators with different foraging behaviours, we estimated the relative exposure of larvae in high and low sites. We evaluate whether: (1) oviposition site affects defence performance against enemies that search exposed or concealed feeding sites; (2) leaf age is associated with defence performance, particularly of the shield defence, which depends on sequestered host chemical precursors; and (3) oviposition site or leaf age alter interactions among defensive traits that increased or decreased larval survival. We will present evidence in support of hypotheses (1), (2) and (3), as well as provide findings that indicate significant leaf age-dependent differences in the availability of chemical precursors, which might account for within-host migration and the differential performance and survival of larvae when attacked by predators.

\section{Materials and methods}

Field site and study system

Adults and larvae of Acromis sparsa (Boheman) feed exclusively on the morning glory vine, Merremia umbellata
(L.) Hallier (Convolvulaceae), which is a common colonist of forest edges, gaps and roadsides throughout Mesoamerica (Windsor, 1987). During the early wet seasons (April-July) of 2007-2010, females of A. sparsa guarding egg masses were located, flagged and monitored on host vines in a large field along Pipeline Road $\left(9^{\circ} 07.6^{\prime} \mathrm{N}, 79^{\circ} 42.5^{\prime} \mathrm{W}: 48 \mathrm{~m}\right)$, near Gamboa, Republic of Panamá. Surrounded by second growth wet forest, the $750 \mathrm{~m}^{2}$ field site, through which a $300 \mathrm{~m}$ network of access trails had been cut, consisted of low shrubs, tree saplings and elephant grass, Saccharum spontaneum, overgrown with M. umbellata vines (Fig. 1b).

\section{Defensive trait manipulations}

Whether the effectiveness of a larval defence, or a combination of defences, is influenced by a female's oviposition site and leaf age decisions can best be determined by experimental defence ablation and subsequent quantification of the interactions between site, age and survival with and without the defence. Given that shields, group size and maternal guarding are physically independent, we were able to manipulate each trait, or combination of traits, by procedures that did not otherwise alter the larvae. When discovered, females with egg masses were randomly assigned to one of nine experimental manipulations. For second to early third instar larvae between 3 and 4 days post-hatch, three defences, maternal guarding, larval shields and group size, were manipulated individually or in all possible combinations, which totalled seven treatments (Table 1). Removal of females eliminated the maternal guarding defence. Shield removal was accomplished by first moving the female aside with a fine paintbrush, then gently lifting the exuvia-faeces complex away from the caudal process with soft forceps. After the shield was removed, faeces did not accumulate on the larval dorsum. Faecal residue on the adjacent leaf surface was removed daily. Group size was reduced to 13-15 larvae by removing individuals with soft forceps. This was half of the mean $( \pm$ SE) brood size of 30.75 (5.6) larvae for the unmanipulated broods. Ablation of all defences left 13-15 larvae vulnerable in a small group. In addition, fully exposed, maternally guarded eggs were monitored from hatching through the larval stage without any defence manipulations. As done during the defence manipulations, the female was brushed aside and the larvae gently stroked with forceps on a daily basis as a sham manipulation (see Vencl \& Srygley, 2013).

Finally, to estimate background mortality due to factors other than predation, an additional treatment was applied to broods within $2 \mathrm{~m}$ of those that had had their defences manipulated. This set of control broods was enclosed in $100 \times 60 \mathrm{~cm}$ cylindrical sleeve cages made of $530 \mu$ Lumite $^{\circledR}$ that effectively excluded all enemies. Table 1 provides samples sizes for the defence manipulations and exclusion experiments.

Larval broods were monitored a minimum of three times daily from 07.00 to 16.00 hours. Only directly observed enemy attacks were recorded. Once a predation event was observed in progress, attacks were monitored until their conclusion, and the number of larvae captured was counted. The presence of an enemy near a brood was noted and closer scrutiny given 
Table 1. Experimental manipulations and resultant defence profiles of Acromis sparsa larvae feeding in different sites and on different leaf ages of its host vine Merremia umbellata.

\begin{tabular}{|c|c|c|c|c|c|c|c|}
\hline \multirow[b]{2}{*}{ Defence manipulation(s) } & \multirow[b]{2}{*}{ Intact defence(s) } & \multirow[b]{2}{*}{$n$ broods } & \multirow[b]{2}{*}{$n$ larvae } & \multicolumn{2}{|l|}{ Site } & \multicolumn{2}{|l|}{ Leaf age } \\
\hline & & & & High & Low & Young & Mature \\
\hline No shield $+\leq 15$ larvae + no female & No defences & 11 & $185^{*}$ & $(5)^{\dagger} 29$ & (6) 156 & (5) 123 & (6) 62 \\
\hline$\leq 15$ larvae + no female & Shield & 13 & $197^{*}$ & (8) 77 & (5) 120 & (5) 60 & (8) 137 \\
\hline No shield + no female & Group & 11 & 305 & (6) 190 & (5) 115 & (5) 123 & (6) 182 \\
\hline No shield $+\leq 15$ larvae & Guarding & 10 & $140^{*}$ & (6) 61 & (4) 79 & (3) 38 & (7) 102 \\
\hline No shield - & Group + guarding & 18 & 666 & (12) 418 & (6) 248 & (3) 45 & (15) 621 \\
\hline$\leq 15$ larvae & Shield + guarding & 17 & $311^{*}$ & (9) 158 & (8) 153 & (7) 116 & (10) 195 \\
\hline$\overline{\text { No female }}$ & Shield + group & 32 & 1118 & (15) 517 & (17) 601 & (18) 578 & $(14) 540$ \\
\hline Intact defences & Shield + group + guarding & 34 & 1125 & (20) 786 & (14) 339 & (11) 327 & (23) 798 \\
\hline Intact defences + exclusion cage & All defences & 11 & 384 & (5) 164 & (6) 220 & (6) 207 & (5) 177 \\
\hline & & 157 & 4431 & (86) 2387 & (71) 2044 & (62) 1634 & (95) 2797 \\
\hline
\end{tabular}

*Number of larvae following group size manipulation, which reduced the number of larvae of the average brood by approximately half.

$\dagger$ Number of broods.

to observe an incipient predation event and to document it in its entirety. Larvae were photographed if they were too small to count by eye ( $<$ third instar). Monitoring of each brood continued until 2-3 days after pupation (20-22 days post-hatch), at which time the pupal mass was collected and transferred to an ambient laboratory at the Smithsonian Tropical Research Institute facility in Gamboa until adult eclosion, or the emergence of parasitoids. The spent egg masses of each brood were collected, its eggs counted, and the exit holes of parasitoid wasps tallied (see Vencl \& Srygley, 2013).

\section{Oviposition site, leaf age, larval migration and apparency}

Each larva was dichotomously scored for the unmanipulated co-factors of oviposition site (high, low) and leaf age (young, mature). Because vines typically grew to $2 \mathrm{~m}$ on the elephant grass trellis (see Fig. 1b), oviposition site was classified into low $(\leq 1 \mathrm{~m})$ or high $(>1 \mathrm{~m}$ above the ground). Leaf age was classified as either young ( $\leq 5$ th), or mature $(>5$ th) leaf. The distance between the apex and fifth leaf was usually less than $50 \mathrm{~cm}$, which placed young and mature leaves in the same light regimen (see below) and level of exposure. The leaf age criterion was derived from previous studies of vines and leaf phenology (Windsor, 1987; Coley et al., 2006).

As an index of larval apparency to predators, we measured the environmental luminous intensity (lux) directly above high and low host leaves with a LI-1000 photometer and quantum series LI-1905B data logger (LI-COR, Lincoln, NE) at midday, 12 June 2008, with sun and large cumulus clouds. Above $1 \mathrm{~m}$, the host vine was usually exposed to direct sunlight (e.g. Fig. 1b).

To quantify the capacity of larvae to adjust maternal oviposition choices, we measured larval migration. The up or down direction of larval emigration on the vine, from the natal leaf, was noted for each brood (i.e. intraplant migration).

\section{Shield metabolites in young and mature leaves}

As a first approximation, we qualitatively measured the differences in available shield defensive precursors between young and mature leaves. Classifying leaf age as above, we gathered between 32 and $50 \mathrm{~g}$ each of fresh young $(n=3)$ and mature leaves $(n=5)$ from separate M. umbellata vines in tortoise beetle habitat at sites in Gamboa and La Vega, Colombia $\left(5^{\circ} 3.53^{\prime} \mathrm{N}, 74^{\circ} 24.08^{\prime} \mathrm{W}\right)$. Plant samples were washed and liquefied in $100 \mathrm{ml}$ methanol $(\mathrm{MeOH})$ until the solution became homogeneous. The solvent was evaporated and the crude extract was dissolved into $50 \mathrm{ml} \mathrm{MeOH}$ and extracted with $20 \mathrm{ml}$ of hexane six times. After partition, the hexanic fraction was solvent-evaporated and analysed by gas chromatography-mass spectrometry by injecting the hexanic, nonpolar fractions into an Agilent 6890N GC, (Agilent Technologies, Santa Clara, California) equipped with a HP-5MS capillary column $(30 \mathrm{~m} \times 0.25 \mathrm{~mm} \times 0.25 \mu \mathrm{m}$ film), and an Agilent $5979 \mathrm{~N}$ mass spectrometer (Agilent Technologies). The temperature was programmed for $70-250{ }^{\circ} \mathrm{C}$ at $15^{\circ} \mathrm{C} \mathrm{min}^{-1}$, post-temperature $280^{\circ} \mathrm{C}$, final hold $5 \mathrm{~min}$, with $1.0 \mu \mathrm{l}$ split injection (split ratio $1: 10$; split flow $0.1 \mathrm{ml} \mathrm{min}^{-1}$ ), injector $250{ }^{\circ} \mathrm{C}$ at constant flow of $0.9 \mathrm{ml} \mathrm{min}^{-1}$. Peaks were identified by computer searches of the Wiley/Demo Mass Spectral Registry (NIST08). Compound elucidations were based on comparisons of mass spectra with MS libraries (Wiley and Wageningen Mass Spectral Databases of the Natural Products). Additional criteria for compound elucidation consisted of co-injection of a series of $n$-alkanes (C8-C24; Sigma-Aldrich, St Louis, Missouri) to calculate compound linear retention indices on the same column, as used above. We then compared the calculated retention indices of peaks from representative samples and from standards, to published values.

\section{Statistical analyses}

We used a log-linear approach, Goodman's $G^{2}$-test, to analyse the three-way contingency table describing the overall associations between oviposition site (high/low), leaf age (young/mature) and parasitisation of eggs by wasps. Seventytwo non-viable eggs were excluded from the analysis because they were neither parasitised by wasps nor hatched. For eggs that hatched, larval survival frequency was the metric we used 
to quantify the net outcome of encounters with predators. Again, we used Goodman's $G^{2}$-test to test the effects of oviposition site and leaf age on the probabilities of fully defended larvae surviving to eclosion. The distribution of young and mature leaves at high and low sites available for oviposition was tested with $\chi^{2}$. For leaf chemistry, the relative mean compound peak areas were compared using a two-tailed, unpaired $t$-test.

For all larvae attacked by identified predators, we used logit regression analysis to detect relationships between predator guild, oviposition site, leaf age, defensive traits and survival. Logit analysis is a more appropriate method than ANOvA when the variables are categorical (e.g. captured/not captured) and is specifically designed to study relationships between more than two discrete response variables (Agresti, 1984). Moreover, logit analyses do not rely on any of the assumptions of parametric statistics.

We ran two non-hierarchical logit models for each predator (ant, wasp, bug) that assessed the relative importance of oviposition site and of leaf age on larval survival. Because selection predominantly acts on individuals, we assumed that each larva was an independent replicate with a specific suite of characteristics affecting its vulnerability. Each larva was coded for oviposition site, leaf age and the presence or absence of a defensive trait, or trait combination as per the experimental manipulations above (e.g. seven combinations of maternally guarded or unguarded, large group or small group resident, and shielded or shield-less). Logit models were calculated by implementing the CATMOD procedure in SAS (v. 9.2, 2009, SAS Institute, Cary, North Carolina). For the model, we used the maximum likelihood method for parameter estimation of linear models and the $\chi^{2}$ statistic for hypothesis testing of the main effects (i.e. young or mature leaf; high or low site) and interactions of the defences with the main effects. Parameter estimates provided quantitative measures of association among variables in the log-linear model and are analogous to ordinary least-squares regression coefficients.

Because each larva occurs within a brood, it is only partly independent when selected for attack by a predator. This is especially the case for traits that are partially correlated, such as the group or guarding defences. Assuming broods were independent observations, we modelled the proportion killed within each brood as the predictor variable with predator, defence, leaf age and site height as the independent variables in a generalised linear model (GLM) with logit link and binomial distribution in JMP (v. 9; SAS Institute). We built the model with main factors and then two-way interactions, selecting the model with the lowest Akaike information criterion that was comparable in structure to the logit models resulting from the CATMOD procedure described above. Three-way interactions resulted in singularities due to small sample sizes and an unbalanced design (e.g. not all three predator types attacked broods with all eight defence combinations on both leaf types at both site heights). Egg parasitism by parasitoid wasps was analysed in a second GLM predicting proportion of eggs parasitised with leaf age and site height

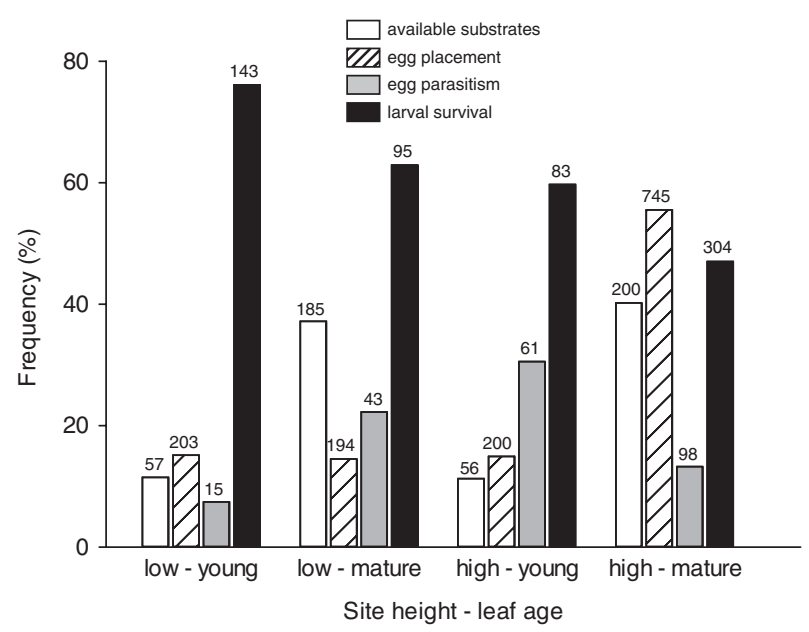

Fig. 2. Availability of oviposition sites, female preferences, egg parasitism rates and survival of fully defended Acromis sparsa larvae on Merremia umbellata. Females strongly preferred to lay their eggs in high sites on mature leaves, although larval survivorship for fully defended larvae was the lowest there. Females selected young over mature leaves in low sites, where survival of fully defended larvae was highest. In high sites, over twice the proportion of eggs were parasitised on young leaves. In low sites, over twice the proportion of eggs were parasitised on mature leaves. Sample sizes are above bars for substrate and oviposition. Numbers of parasitised eggs and surviving larvae are given above the egg mortality and larval survivorship bars.

as the independent variables (defences were unmanipulated at this stage).

\section{Results}

Overall, females were more likely to lay their eggs on mature leaves in high sites $\left(G^{2}=114.6\right.$, d.f. $=1, P<0.001$; Fig. 2$)$. Given the prevalence of mature leaves in both high and low sites $\left(\chi^{2}=0.2\right.$; d.f. $=1 ; P=0.65$; Fig. 2$)$, females not only showed a preference for mature leaves in high sites but an avoidance of mature leaves in low sites. Analysis of brood placement yielded the same conclusion. Females preferred high, mature leaves and avoided low, mature leaves despite the prevalence of the latter $\left(\chi^{2}=5.6\right.$; d.f. $\left.=1 ; P=0.018\right)$.

The proportion of eggs parasitised by wasps did not differ between high and low sites $\left(G^{2}=1, P=0.32\right)$ or between young and mature leaves $\left(G^{2}=3, P=0.08\right)$. However, female selection of leaves in high and low sites was consistent with avoidance of egg parasitoids. In high sites, females preferred to lay and guard offspring on mature leaves, and eggs on young leaves were more than twice as likely to be parasitised by wasps than those on mature ones $\left(30 \%\right.$ vs. $13 \%, G^{2}=30.3$, $P<0.001)$. In contrast, in low sites, females preferred to lay eggs on young leaves, and eggs on mature leaves were four times as likely to be parasitised by wasps as those on young leaves $\left(28 \%\right.$ vs. $\left.7 \%, G^{2}=17.9, P<0.001\right)$.

Analysis of the proportion of eggs in a brood that was parasitised showed qualitatively similar results. Parasitism was affected by site height, leaf age and the interaction between site 
height and leaf age (GLM $\chi^{2}=44.6$, d.f. $\left.=3, P<0.0001\right)$. Higher broods were more likely to be parasitised $\left(\chi^{2}=9.4\right.$, d.f. $=1, P=0.0021)$, but leaf age was not a significant factor $\left(\chi^{2}=0.2\right.$; d.f. $\left.=1 ; P=0.68\right)$. Moreover, higher broods on young leaves and lower broods on mature leaves had a greater proportion of eggs parasitised $\left(\chi^{2}=38.6\right.$, d.f. $=1$, $P<0.0001)$.

For eggs that hatched, female preferences had serious consequences for the risk of predation on fully defended larvae (Fig. 2). Survivorship was significantly greater in low versus high oviposition sites $\left(G^{2}=43.2\right.$, d.f. $\left.=1, P<0.001\right)$, and it was greater on young versus mature leaves $\left(G^{2}=35.1\right.$, d.f. $=1, P<0.001)$. Hence, female preference to lay and guard offspring on high, mature leaves was at odds with the low survivorship of larvae there $(47 \%)$, whereas female avoidance of mature leaves in low sites was consistent with the highest survivorship on low, young leaves (76\%, Fig. 2). Analyses of the proportion of fully defended larvae in a brood that were killed by predators showed qualitatively similar results. Mortality was significantly affected by site height and leaf age $\left(\mathrm{GLM} \chi^{2}=46.1\right.$, d.f. $\left.=2, P<0.0001\right)$. Survivorship was significantly greater in high versus low oviposition sites $\left(\chi^{2}=9.4\right.$, d.f. $\left.=1, P=0.0021\right)$, and it was greater on young versus mature leaves $\left(\chi^{2}=40.1\right.$, d.f. $\left.=1, P<0.0001\right)$. Thus, we find that the results are at odds with female preference for oviposition on mature leaves in high sites but consistent with female avoidance of mature leaves in low sites.

The most common predators observed attacking A. sparsa larvae fell into three functionally distinct trophic guilds, which used different combinations of locomotion, orientation cues and handling tactics: (1) ants: chemical/pedestrian/mandibulate/recruiting (four spp.); (2) predatory wasps: visual + chemical/aerial/mandibulate (two spp.); and (3) bugs: pedestrian/stalking + sit-and-wait/hausellate (sucking-piercing) (four spp.). Nymphal katydids, eulophid parasitoid wasps and tachinid parasitoid flies were minor larval enemies $(<1 \%)$. As an overall baseline, larvae with intact defences suffered considerable losses from all three predator guilds, ranging between $38 \%$ and $60 \%$ (dashed lines in Figs 3 and 4). In this paper, species within a guild are pooled together and hereafter referred to as ants, wasps, or bugs, and the three guilds are collectively referred to as predators.

\section{Effect of oviposition site on defence performance and larval survival}

In general, the risk of ant predation for a larva feeding in a low site was significantly higher than for its counterpart in a high site (Fig. 3; Table 2). Oviposition site significantly affected defence performance against ants. Maternally guarded larvae with intact shields living in small groups suffered significantly lower survival in low sites, whereas these same defences resulted in greater larval survival in high sites (Fig. 3). When group size was reduced, larvae in high sites experienced significantly higher mortality from ants, even though the larvae still had their shields and were guarded. Thus, maternal guarding and large larval groups were the most important defences in high sites. However, without shields and large broods, maternal guarding became a liability at low sites against ants.

Survival was lower, but not significantly so, for larvae in high sites attacked by both bugs or by wasps (Fig. 3). However, oviposition site significantly affected defence performance against wasps. Removal of the mother resulted in significantly greater mortality from wasps in high sites, whereas removal of the shield and the mother resulted in significantly greater mortality in low sites from this same enemy. In sum, maternal guarding was responsible for survivorship from wasp attacks in high sites, whereas both shields and maternal guards were needed for survival in low sites.

With removal of guarding mothers, larvae with shields and living in large groups were significantly more vulnerable to bug attack irrespective of oviposition site (Fig. 3). Removal of shields and maternal guards resulted in increased survivorship from bug attacks at high sites, whereas these same manipulations resulted in lower survival in low sites. Reducing group size greatly increased mortality at the high sites, perhaps because bugs no longer could become satiated. On the other hand, survival was somewhat greater for maternally guarded larvae lacking shields and residing in small broods. Whereas group size and guarding were the most important defences against bugs in both high and low sites, shields actually reduced survival against bugs in high sites.

The proportion of larvae in a brood that were killed was significantly affected by an interaction between site height and predator guild (GLM $\chi^{2}=17.9$, d.f. $=2, P=0.0001$; Tables S1 and S2). Mortality from ant predation was significantly greater in low versus high sites, whereas mortality from bug predation was significantly greater in high versus low sites. The proportion of larvae in a brood that were killed was significantly affected by an interaction between site height and defence (GLM $\chi^{2}=60.6$, d.f. $=7, P<0.0001$ ). Those with shields removed had less mortality at low sites and greater mortality at high sites. Those with group size diminished had less mortality at low sites and greater mortality at high sites. In contrast to those in smaller groups, broods with their group sizes diminished and their guards removed had greater mortality at low sites but less at high sites.

\section{Effect of leaf age on defence performance and larval survival}

Leaf age significantly altered the pattern of larval defence efficacy and survival rates against ants. Overall, shielded larvae in large groups suffered lower survival against ants. Whereas feeding on mature leaves generally decreased their survival, larvae with only shields that were derived from young leaves fared significantly better against ants (Fig. 4; Table 3). However, shields derived from mature leaves, in combination with large broods, produced significantly higher survival rates than shields alone (Fig. 4). Survival was also reduced against ants for shield-less, but guarded larvae in large groups on mature leaves.

There were significant correlations between the leaf age and vulnerability to other predators. As observed with larvae attacked by ants, a diet of mature leaves significantly reduced survival against wasps (Fig. 4; Table 3). On the other hand, 
Significant main effects

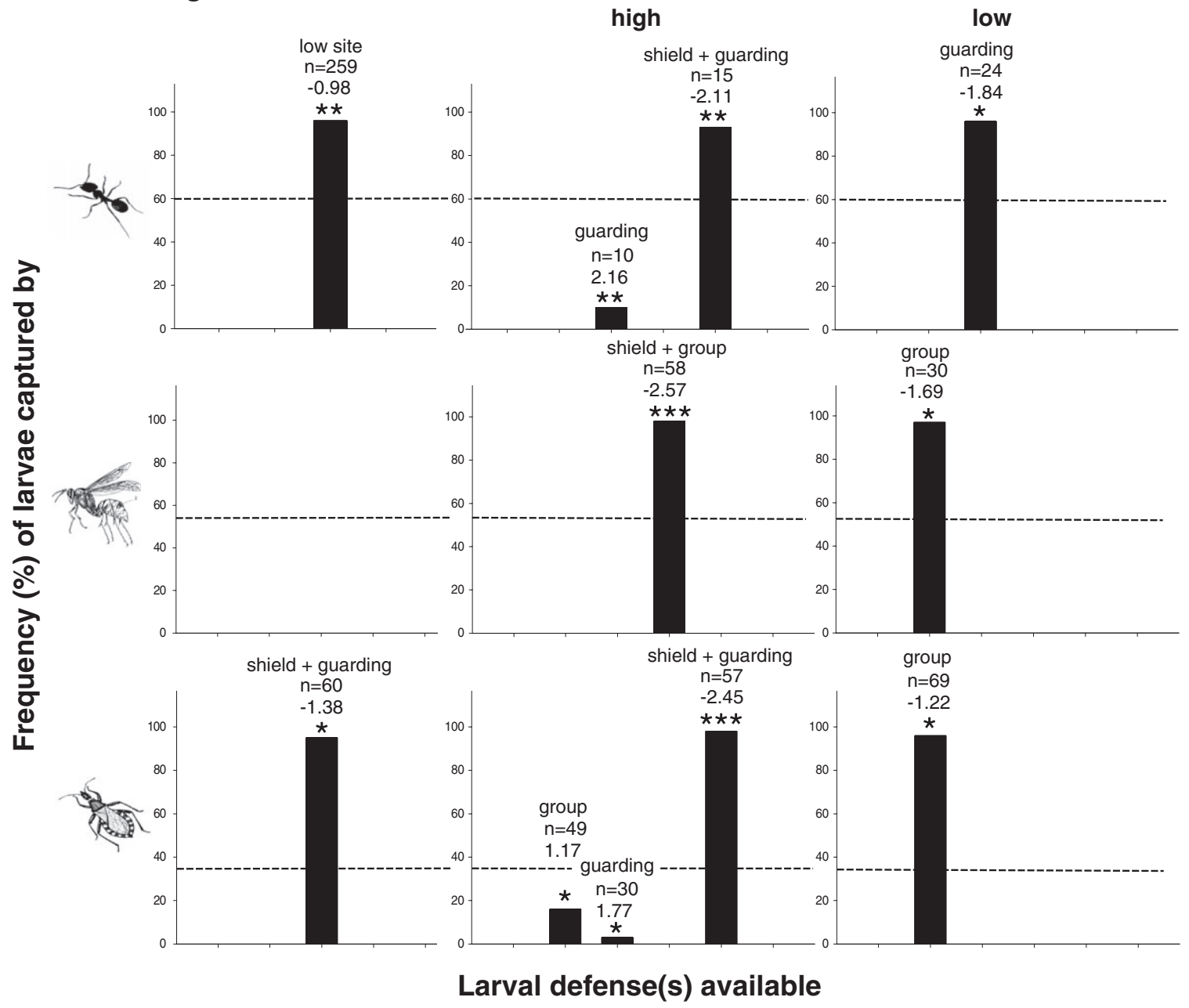

Fig. 3. Impact of oviposition site and predator guild on defence efficacy and survival of Acromis sparsa larvae. Bars depict the frequency of captured larvae by a given predator guild. As a baseline, dashed lines indicate the level of mortality inflicted on fully defended larvae by a given predator guild. Sample size, slope and significance of the regression coefficient $\left({ }^{*} P=0.05 ; * * P=0.01 ; * * * P<0.0001\right)$ are given above each bar. Only significant main effects and their interactions from the maximum likelihood analysis are shown.

shields derived from young leaves significantly increased survival against wasps. In contrast to both ants and wasps, larvae feeding on younger leaves had significantly lower survival frequencies during encounters with bugs. Moreover, when shields derived from young leaves were combined with large groups larvae were rendered even more vulnerable to bugs (Fig. 4).

The proportion of larvae in a brood that were killed was significantly affected by an interaction between leaf age and predator guild (GLM $\chi^{2}=16.5$, d.f. $=2, P=0.0003$; Tables $\mathrm{S} 1$ and S2). More larvae were killed by ants on young leaves than they were on mature leaves. However, more larvae were killed by wasps on mature leaves versus young leaves. The proportion of larvae in a brood that were killed was significantly affected by an interaction between leaf age and defence (GLM $\chi^{2}=60.6$, d.f. $\left.=7, P<0.0001\right)$. Those with guards removed had greater mortality on mature leaves, surviving better on young leaves. Those with shields removed had greater mortality on young leaves, while more survived on mature leaves. In contrast to those with only their shields removed, de-shielded larvae residing in broods with reduced size had less mortality on young leaves and greater mortality on mature leaves.

\section{Survival of caged control and defenceless larvae}

Although they suffered appreciable mortality, fully defended larvae enclosed in cages that excluded all enemies enjoyed the highest larval survival frequency $(77 \%)$. There were no detectable effects of either oviposition site or of leaf age on the survival of fully defended, caged larvae $\left(\chi^{2}=1.39, P=0.24\right.$; $\chi^{2}=1.06, P=0.74$, respectively; $\left.n=384\right)$. Irrespective of leaf age or feeding site, more than $95 \%$ of completely exposed and defenceless larvae were killed within 7 days of hatching. 


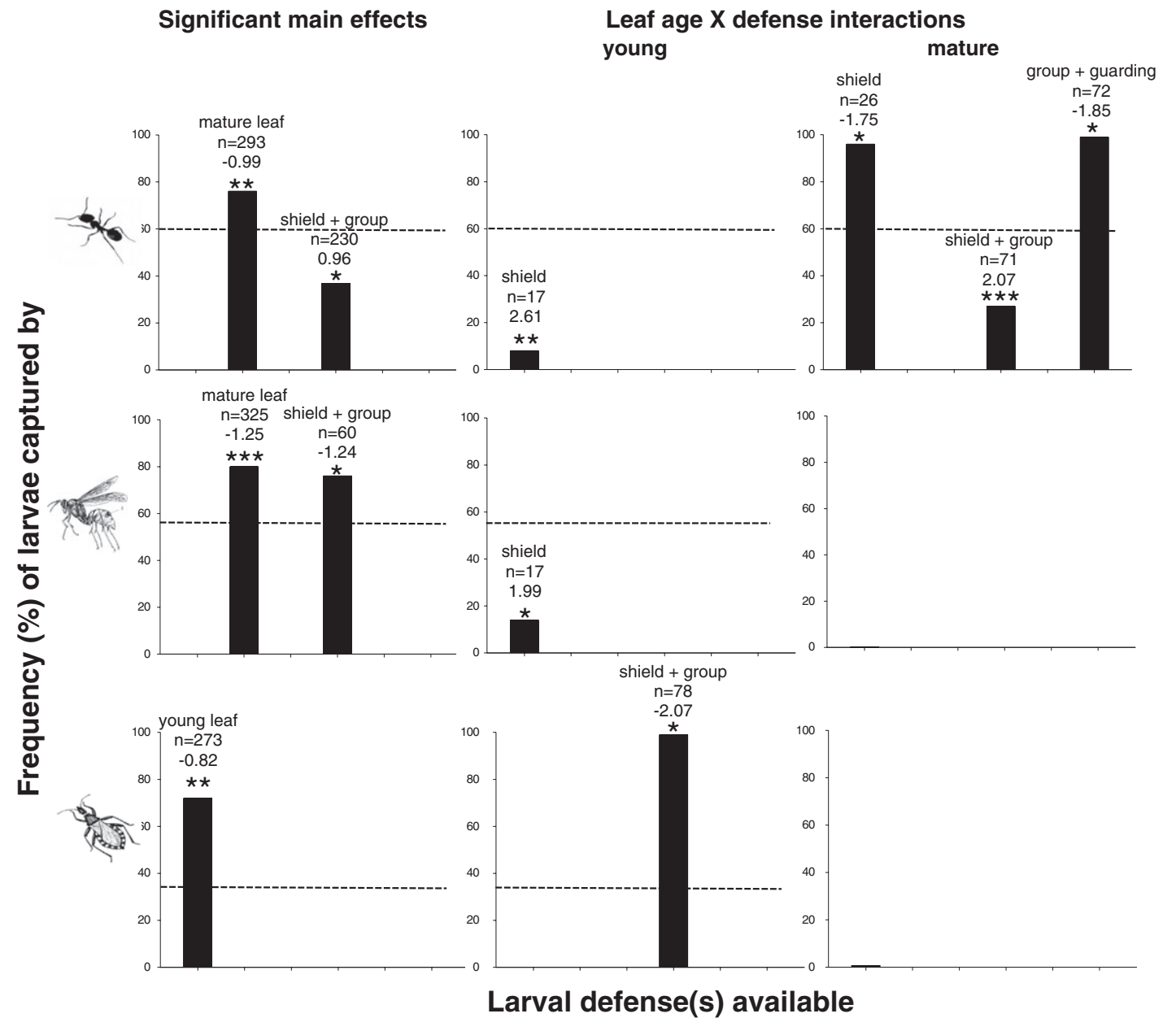

Fig. 4. Impact of leaf age and predator guild on defence efficacy and survival of Acromis sparsa larvae. As a baseline, dashed lines indicate the level of mortality inflicted on fully defended larvae by a given predator guild. Bars depict frequency of larvae captured by a given, ant, bug or wasp predator guild. Legends as in Fig. 3. Only significant main effects and interactions from the maximum likelihood analysis are shown.

Table 2. Maximum likelihood ANOva derived from logit regression models of survivorship from each predator attributed to oviposition site, larval defence and their interaction.

\begin{tabular}{llrrc}
\hline Predator & Source & d.f. & \multicolumn{1}{c}{$\chi^{2}$} & \multicolumn{1}{l}{$P$} \\
\hline Ant & Oviposition site & 2 & 9.38 & 0.009 \\
& Defence & 7 & 2.78 & 0.905 \\
& Site $\times$ defence & 14 & 24.77 & 0.04 \\
Wasp & Oviposition site & 2 & 2.49 & 0.288 \\
& Defence & 7 & 2.99 & 0.886 \\
& Site $\times$ defence & 14 & 43.89 & $<0.0001$ \\
Bug & Oviposition site & 2 & 3.97 & 0.137 \\
& Defence & 7 & 7.24 & 0.403 \\
& Site $\times$ defence & 14 & 56.07 & $<0.0001$ \\
\hline
\end{tabular}

\section{Oviposition behaviour, larval migration and apparency}

In preparation for oviposition on the abaxial leaf surface, mothers scored the leaf mid-vein, which resulted in partial wilting of the leaf's distal portion. Consequently, leaves
Table 3. Maximum likelihood ANOva derived from logit regression models of survivorship from each predator attributed to leaf age, larval defence and their interaction.

\begin{tabular}{llrrc}
\hline Predator & Source & d.f. & \multicolumn{1}{c}{$\chi^{2}$} & \multicolumn{1}{c}{$P$} \\
\hline Ant & Leaf age & 2 & 15.42 & 0.0004 \\
& Defence & 7 & 11.46 & 0.120 \\
\multirow{3}{*}{ Wasp } & Leaf age $\times$ defence & 14 & 62.89 & $<0.0001$ \\
& Leaf age & 2 & 16.10 & 0.0003 \\
& Defence & 7 & 11.97 & 0.102 \\
Bug & Leaf age $\times$ defence & 14 & 17.76 & 0.218 \\
& Leaf age & 2 & 8.05 & 0.017 \\
& Defence & 7 & 7.01 & 0.428 \\
& Leaf age $\times$ defence & 14 & 15.01 & 0.038 \\
\hline
\end{tabular}

became slightly deflected downward to assume an umbrellalike shape, which served to conceal females and their egg masses from above (Windsor, 1987). After reaching the third instar, larval broods migrated from the natal leaf to consume two to four more leaves before pupation. The direction 
Table 4. Relative amounts of two shield defensive precursors found in young and mature Merremia umbellata leaves.

\begin{tabular}{|c|c|c|c|c|c|c|c|c|}
\hline \multirow[b]{2}{*}{ Compound } & \multirow[b]{2}{*}{$\mathrm{RI}^{*}$} & \multirow[b]{2}{*}{$\mathrm{RT}^{\dagger}$} & \multirow[b]{2}{*}{$\mathrm{m} / \mathrm{z}^{\ddagger}$} & \multirow[b]{2}{*}{ d.f. } & \multicolumn{4}{|l|}{ Leaf age } \\
\hline & & & & & $\begin{array}{l}\text { Young } \\
\text { Peak area }(\mathrm{SE})^{\S}\end{array}$ & $\begin{array}{l}\text { Mature } \\
\text { Peak area (SE) }\end{array}$ & $t^{\mathbb{I}}$ & $P$ \\
\hline Phytol & 2142 & $16.46-18.87$ & 296 & 6 & $21.83(2.86)$ & 44.44 (11.27) & 2.49 & 0.046 \\
\hline Oleic acid & 2208 & $16.67-19.00$ & 284 & 4 & $4.37(0.22)$ & $2.62(0.21)$ & 5.64 & 0.0049 \\
\hline
\end{tabular}

*Retention indices.

$\dagger$ Retention time (min).

$\$$ Molecular ion.

$\S$ Mean (standard error).

IIUnpaired, two-tailed $t$-test.

of intraplant migration was dependent on the age of the natal leaf. Broods hatching on young leaves more frequently migrated down the vine (down/up, $61: 23$; two-tailed binomial; $P<0.0001)$. Broods hatching on mature leaves most often migrated up the vine to feed on younger leaves (down/up, 12 : 43; two-tailed binomial; $P<0.0001$ ).

As a proxy for larval apparency, light intensities measured on leaves at less than $1 \mathrm{~m}$ above ground averaged $95 \operatorname{lux}(n=7$; range: $39-181$ lux $)$. Above $1 \mathrm{~m}$, light intensities averaged $105000 \operatorname{lux}(n=6$; range: $8.9-122 \mathrm{Klux})$.

\section{Leaf age and the availability of shield chemical precursors}

The chemical analysis revealed that both young and mature leaves of M. umbellata contained relatively large amounts of free phytol, as well as a suite of several fatty acid derivatives in relatively smaller quantities, including palmitic (hexadecanoic) and oleic (octadecanoic) acids. Mature leaves had nearly twice the relative concentration of phytol than young leaves, but young leaves had greater relative amounts of octadecanoic (oleic) acid than mature leaves (Table 4).

\section{Discussion}

The working hypothesis of this study was to test whether or not a mother's proximate oviposition behaviour (site and leaf choices) influenced subsequent larval defence performance and survival. On average, we found that females of Acromis sparsa, a dietary specialist, strongly preferred to lay their eggs on mature leaves of the host vine that were situated well above the ground, but avoided mature leaves near to the ground. The impacts of these opposing patterns of site-leaf preferences were different for eggs and fully defended larvae. Whereas the avoidance of egg parasitoids and higher survivorship of fully defended larvae both reinforced female preference for young leaves in low sites, these same mortality factors were in conflict at high sites, where mortality due to egg parasitism was significantly lower but larval mortality was significantly higher on mature leaves.

Like many other herbivorous bugs, beetles, sawflies and Lepidoptera with ectophytic immatures, A. sparsa's larvae suffered very high mortality in the field, despite their complex defence arsenal. Although we could not account for every larva lost, we believe that the level of mortality due to predation (about $60 \%$ ) was sufficiently robust to quantify the impacts of oviposition site and leaf age on larval survival against the milieu of sympatric predators. Because of the large taxonomic differences, broad diets and distinct modes of attack among the three predatory guilds (ant, wasp, bug) most often observed at this field site, the results of this study could be generalised to a wide diversity of other invertebrate predators using respectively similar means of attack. For example, over $70 \%$ of reported tortoise beetle larval predators have piercing/sucking mouthparts (Cox, 1996). Exemplars from all of the same predator guilds we observed frequently attack other tortoise beetle species in tropical (Windsor, 1987; Gómez, 2004; Vencl et al., 2005) and in temperate communities (Olmstead \& Denno, 1993; Olmstead, 1996; Bacher \& Luder, 2005).

\section{Oviposition site and defence performance}

Theory predicts that natural variation in exposure, among other factors, can affect predation risk by changing prey apparency to predators (Abrams, 1993). At the spatial scale of the present study, vegetative architecture, as measured by available light, was a significant predictor of apparency to particular predator guilds. We observed that the majority of A. sparsa females oviposited on mature leaves well above the ground, which rendered larvae more vulnerable to bugs and wasps. On the other hand, low sites, due to entangling foliage, had over three orders of magnitude lower light intensities than high sites. Larvae were likely afforded much greater concealment from visually orienting, sit-and-wait predators, such as bugs. Consistent with this observation, reduced survival frequencies were correlated with higher rates of bug attacks in high sites. Whereas wasps, which also hunt visually by means of aerial patrolling, were threats at all levels of concealment, ants were the most abundant and important predators on or near the ground in more occluded sites as they generally are in tropical lowland rain forests (Hölldobler \& Wilson, 1990; Novotny et al., 1999).

Oviposition site was a significant predictor of not only a larva's exposure to certain predatory guilds, but also whether a defence would be effective against a given guild. All defences lacked cross-resistance. For example, guarding by itself significantly increased survival only against ants and 
bugs attacking larvae in high sites. When deployed with shields, however, guarding was not effective against these same enemies. The negative interaction between guarding and shields suggests that shields somehow confound guarding, perhaps by inadvertently acting as a signal benefiting predators, a possibility we discuss below.

Larvae assembled in large groups appeared to be attractive to wasps in both high and low sites, particularly if they also had shields. Social vespids, such as Polybia rejecta, are opportunistic, generalist foragers. Individuals often return to hunt in sites of previous success or with high prey density, thus functioning temporarily as 'specialists' (Richter, 2000). Type II functional responses, in which the attack rate increases at a declining rate with prey density until satiation, are typical of opportunistic generalists, such as $P$. rejecta, that specialise on aggregated prey (Schenk \& Bacher, 2002). Unlike Polistes diminulus, which preferred to attack solitary larvae of the tortoise beetle Cassida rubiginosa in more open sites (Tschanz et al., 2005), the negative slopes for site by group interactions indicated that large $A$. sparsa aggregations made larvae more attractive to $P$. rejecta, regardless of whether they were apparent or concealed. Similarly, shielded larvae had much shorter survival times against wasps, which suggests that not only are shields ineffective, but that they may actually attract wasps (e.g. Schaffner \& Müller, 2001). Vespid wasps are well known to associate both colour and odour with food rewards (McPheron \& Mills, 2007). A large group clearly represents a concentrated resource. If shields act as beacons, then aggregated larvae in exposed sites would be particularly vulnerable, an idea consistent with greater waspinduced mortality of aggregated, shielded larvae found in high sites. Maternal guarding, on the other hand, is an effective defence against vespid wasps (Vencl \& Srygley, 2013). The shield and guarding defences also interacted negatively to reduce survival against bugs for larvae in high sites. A lack of broods with every defence combination attacked by each predator at each site did not permit an independent evaluation of these conclusions. Because the group defence by itself was quite effective against bugs (see Vencl \& Srygley, 2013), shields might act as beacons, a finding we consider below in connection with leaf chemistry.

\section{Leaf age impact on defence effectiveness and larval migration}

We expected that because young leaves of many tropical plants rely on chemical defences, while mature leaves depend mainly on toughness to thwart herbivory (Kursar \& Coley, 2003), A. sparsa larvae would have higher survival on young leaves because they would be richer in sequesterable defensive metabolites. Consistent with an earlier study (Windsor, 1987), most females did lay their eggs on mature leaves. However, mature leaves were not associated with higher shield performance against all predatory guilds. Whereas a diet of young leaves increased shield effectiveness against ants, mature leaves appeared to reduce shield efficacy against bugs. These effects may be correlated with the relative availability of two important shield defensive precursors, phytol and oleic (octadecanoic) acid. Our chemical analysis revealed that younger leaves have less phytol and more oleic acid compared to mature leaves. Both phytol and oleic acid have been previously shown to be ant deterrents in tortoise beetle and other shield systems (Morton \& Vencl, 1998; Vencl et al., 1999). For example, oleic acid elicited necrophorasy in ants: any item, such as a shield concealing a larva, which emits this fatty acid, will be discarded on the nest trash heap, thus affecting a larva's escape. Consistent with this observation is our finding that shields made from younger leaves, with higher relative concentrations of oleic acid, are much more effective against ants. However, some predators may use the same shield compounds, such as volatile terpenoids that repel most enemies (Gómez et al., 1999), to locate tortoise beetle larvae (Müller \& Hilker, 1999). For example, phytol has been shown to act as a short distance kairomone and to elicit beak extension in a predatory bug (Yasuda, 1998). According to our findings, phytol is more concentrated in mature leaves. The fact that shields derived from mature leaves nearly doubled the risk of bug attack is consistent with the idea that phytol may act as a beacon that attracts predatory bugs. More research on the effects of chemicals sequestered from the host plant on defences against enemies is warranted. Analysis of the proportion of larvae killed within broods suggests that ant mortality was greater on young leaves, which implies that phytol, which was less concentrated in the young leaves, may be a greater contributor to defence against ants than oleic acid, which was more concentrated in young leaves. Moreover, mortality due to vespid wasps was greater on mature leaves, suggesting that phytol might act as a kairomone, or beacon, for wasps, as well as for bugs.

According to the enemy-free space hypothesis, host plants can provide herbivores various kinds of refugia from predation. Chief among such refugia are sequesterable defensive metabolites. From a female herbivore's perspective, chemical refugia can vary at several relevant spatial scales, such as within habitats, among hosts or between host tissues. Our findings support the idea that differences in chemistry among adjacent leaves on the same plant can affect the survival of immature herbivorous insects, especially for diet-specialised species such as A. sparsa (Kouki, 1993; Lill et al., 2001; Boege, 2005; Peñuelas et al., 2006). Because of Merremia's vine growth habit, leaf flushing is rapid, decreasing chronologically from the vine apex. Consequently, larvae encounter gradients in leaf nutritional quality, sequesterable defensive precursors, and in vulnerability to predators. Rapid leaf flushing (2-3 days) represents a very short window in which to obtain high levels of defensive precursors such as free fatty acids. Intra-host larval migration data demonstrated that most larvae attempted to feed on younger leaves for at least part of their development. These data further suggest that larvae may be able to detect differences in phenology, or in chemical traits, related to leaf age that may guide them to obtain a better balance of defensive metabolites.

We conclude that the mother's proximate site and leaf choices may be at odds with the best interests of her progeny. Larval migration to leaves of different age from that of the natal leaf may mitigate within-host trade-offs between defence performance and vulnerability to specific predators, 
and broaden access to sequesterable defensive precursors. Guarding and migration may represent behavioural adaptations critical to the exploitation of enemy-free space by specialists (e.g. Jeffries \& Lawton, 1984; Stamp \& Bowers, 1996). The impact of the third trophic level on patterns of larval insect grazing, especially of ectophytic specialists, which feed openly on a few closely related, or even a single host species, are not well documented in tropical communities, where predation may be higher than in their temperate counterparts (Mooney et al., 2012). Moreover, there has been almost no research measuring the importance of oviposition site with respect to enemy apparency in tropical herbivorous insects (Dyer \& Coley, 2002). Our findings support the idea that oviposition behaviour predisposes selection whereby host plant architecture and leaf chemistry can interact to influence larval vulnerability to specific enemy guilds.

\section{Acknowledgements}

We are most grateful to two anonymous reviewers for many comments that significantly improved the paper. We thank B. Turner for loan of the photometer and data logger. We are grateful to N. Rivas and N. Gómez for additional chemical analyses. We thank CIMPAT, Química de Aromas laboratories and J. Molina for chemical analytic support. J. Gaskin made useful comments on the paper. Experiments and specimen collection were done under permits issued by the Authoridad Nacional del Ambiente de Panamá (ANAM). This is contribution \#1215 from the Department of Ecology and Evolution at Stony Brook University.

\section{Supporting Information}

Additional Supporting Information may be found in the online version of this article under the DOI reference:

\subsection{1/een.12052}

Table S1. Generalised linear model (GLM) with main effects and two-way interactions that minimised the Akaike information criterion.

Table S2. The coefficients resulting from the GLM for predicting the number of larvae killed within each brood and $\chi^{2}$ tests of statistical significance of each coefficient.

\section{References}

Abrams, P.A. (1993) Why predation rate should not be proportional to predator density. Ecology, 74, 726-733.

Agresti, A. (1984) Analysis of Ordinal Categorical Data. John Wiley and Sons, New York, New York.

Awmack, C.S. \& Leather, S.R. (2002) Host plant quality and fecundity in herbivorous insects. Annual Review of Entomology, 47, 817-844.

Bacher, S. \& Luder, S. (2005) Picky predators and the function of the faecal shield of a cassidine larva. Functional Ecolology, 19, 263-272.

Ballabeni, P., Wlodarczyk, M. \& Rahier, M. (2001) Does enemy-free space for eggs contribute to a leaf beetle's oviposition preference for a nutritionally inferior host plant? Functional Ecology, 15, 318-324.
Berenbaum, M.R. \& Zangerl, A.R. (1998) Chemical phenotype matching between a plant and its insect herbivore. Proceedings of the National Academy of Sciences of the United States of America, 95, 13743-13748.

Bernays, E.A. \& Chapman, R.F. (1994) Host-Plant Selection by Phytophagous Insects. Chapman \& Hall, New York, New York.

Bernays, E.A., Singer, M.S. \& Rodrigues, D. (2004) Foraging in nature: foraging efficiency and attentiveness in caterpillars with different diet breadths. Ecological Entomology, 29, 389-397.

Björkman, C., Larsson, S. \& Bommarco, R. (1997) Oviposition preferences in pine sawflies: a trade-off between larval growth and defence against natural enemies. Oikos, 79, 45-52.

Boege, K. (2005) Herbivore attack in Casearia nitida influenced by plant ontogenetic variation in foliage quality and plant architecture. Oecologia, 143, 117-125.

Clark, K.E., Hartley, S.E. \& Johnson, S.N. (2011) Does mother know best? The preference-performance hypothesis and parent-offspring conflict in above ground-below ground herbivore life cycles. Ecological Entomology, 36, 117-124.

Coley, P.D., Bateman, M.L. \& Kursar, T.A. (2006) The effects of plant quality on caterpillar growth and defense against natural enemies. Oikos, 115, 219-228.

Cox, M.L. (1996) Insect predators of the Chrysomelidae. Chrysomelidae Biology. Ecological Studies, Vol. 2 (ed. by P. H. A. Jolivet and M. L. Cox), pp. 23-91. SPB Academic Publishing, Amsterdam, The Netherlands.

De-Silva, D.L., Vasquez, A.S. \& Mallet, J. (2011) Selection for enemyfree space: eggs placed away from the host plant increase survival of a neotropical ithomiine butterfly. Ecological Entomology, 36, 667-672.

Dyer, L.A. \& Coley, P.D. (2002) Tritrophic interactions in tropical versus temperate communities. Multitrophic Level Interactions (ed. by T. Tscharntke and B.A. Hawkins), pp. 67-88. Cambridge University Press, New York, New York.

Gómez, N.E. (2004) Survivorship of immature stages of Eurypedus nigrosignatus Boheman (Chrysomelidae: Cassidinae: Physonotini) in central Panama. Coleopterists Bulletin, 58, 489-500.

Gómez, N.E., Witte, L. \& Hartmann, T. (1999) Chemical defense in larval tortoise beetles: essential oil composition of fecal shields of eurypedus nigrosignata and foliage of its host plant, Cordia curassavica. Journal of Chemical Ecology, 25, 1007-1027.

Gripenberg, S., Mayhew, P.J., Parnell, M. \& Roslin, T. (2010) A metaanalysis of preference-performance relationships in phytophagous insects. Ecological Letters, 13, 383-393.

Heisswolf, A., Obermaier, E. \& Poethke, H.J. (2005) Selection of large host plants for oviposition by a monophagous leaf beetle: nutritional quality or enemy-free space? Ecological Entomology, 30, 299-306.

Hölldobler, B. \& Wilson, E.O. (1990) The Ants. Harvard University Press, Cambridge, Massachusetts.

Jaenike, J. (1978) On optimal oviposition behaviour in phytophagous insects. Theories in Population Biology, 14, 350-356.

Jeffries, M.J. \& Lawton, J.H. (1984) Enemy free space and the structure of ecological communities. Biological Journal of the Linnean Society, 23, 269-286.

Kouki, J. (1993) Female's preference for oviposition site and larval performance in the water-lily beetle, Galerucella nymphaeae (Coleoptera: Chrysomelidae). Oecologia, 93, 42-47.

Kursar, T.A. \& Coley, P.D. (2003) Convergence in defense syndromes of young leaves in tropical rainforests. Biochemical Systematics and Ecology, 21, 929-949.

Larsson, S. \& Ohmart, C.P. (1988) Leaf age and larval performance of the leaf beetle Paropsis atomaria. Ecological Entomology, 13, $19-24$. 
Larsson, S., Haggstrom, H.E. \& Denno, R.F. (1997) Preference for protected feeding sites by larvae of the willow-feeding leaf beetle Galerucella lineola. Ecological Entomology, 22, 445-452.

Lill, J.T., Marquis, R.J. \& Ricklefs, R.E. (2001) The effects of leaf quality on herbivore performance and attack from natural enemies. Oecologia, 126, 418-428.

Mayhew, P.J. (1997) Adaptive patterns of host plant selection by phytophagous insects. Oikos, 79, 417-428.

McPheron, L.J. \& Mills, N.J. (2007) Discrimination learning of color-odor compounds in a paper wasp (Hymenoptera: Vespidae: Pompilinae: Mischocyttarus flavitarsis). Entomologia Generalis, 29, $125-134$.

Moon, D.C. \& Stirling, P. (2006) Trade-off in oviposition strategy: choosing poor quality host plants reduces mortality from natural enemies for a salt marsh planthopper. Ecological Entomology, 31, $236-241$

Mooney, K.A., Pratt, R.T. \& Singer, M.S. (2012) The tri-trophic interactions hypothesis: interactive effects of host plant quality, diet breadth and natural enemies on herbivores. PLOS ONE, 7, e34403.

Morton, T.C. \& Vencl, F.V. (1998) Larval beetles (Chrysomelidae: Criocerinae) form defense from recycled host compounds discharged as fecal wastes. Journal of Chemical Ecology, 24, $765-786$

Müller, C. \& Hilker, M. (1999) Unexpected reactions of a generalist predator towards defensive devices of cassidine larvae (Coleoptera: Chrysomelidae). Oecologia, 118, 166-172.

Nishida, R. (2002) Sequestration of defensive substances from plants by lepidoptera. Annual Review of Entomology, 47, 57-92.

Novotny, V., Basset, Y., Auga, J., Boen, W., Dal, C., Drozd, P., et al. (1999) Predation risk for herbivorous insects on tropical vegetation: a search for enemy-free space and time. Australian Journal of Ecology, 24, 477-483.

Nylin, S. \& Janz, N. (1993) Oviposition preference and larval performance in Polygonia c-album (Lepidoptera: Nymphalidae)-the choice between bad and worse. Ecological Entomology, 18, 394-398

Olmstead, K.L. (1996) Cassidine defenses and natural enemies. Chrysomelidae Biology. Ecological Studies, Vol. 2 (ed. by P.H.A. Jolivet and M. L. Cox), pp. 3-21. SPB Academic Publishing, Amsterdam, The Netherlands.

Olmstead, K.L. \& Denno, R.F. (1993) Effectiveness of tortoise beetle larval shields against different predator species. Ecology, 74, 1394-1405.

Oppenheim, S.J. \& Gould, F. (2002) Behavioral adaptations increase the value of enemy free space for Heliothis subflexa, a specialist herbivore. Evolution, 56, 679-689.

Pearse, I.S. (2011) The role of leaf defensive traits in oaks on the preference and performance of a polyphagous herbivore, Orgyia vetusta. Ecological Entomology, 36, 635-642.

Peñuelas, J., Sardans, J., Stefanescu, C., Parella, T. \& Filella, I. (2006) Lonicera implexa leaves bearing naturally laid eggs of the specialist herbivore Euphydryas Aurinia have dramatically greater concentrations of iridoid glycosides than other leaves. Journal of Chemical Ecology, 32, 1925-1933.
Richter, R.M. (2000) Social wasp (Hymenoptera: Vespidae) foraging behavior. Annual Review of Entomology, 45, 121-150.

Schaffner, U. \& Müller, C. (2001) Exploitation of the faecal shield of lily leaf beetle, Lilioceris lilii (Coleoptera: Chrysomelidae), by the specialist parasitoid Lemophagus pulcher (Hymenoptera: Ichneumonidae). Journal of Insect Behavior, 14, 739-757.

Schenk, D. \& Bacher, S. (2002) Functional response of a generalist insect predator to one of its prey species in the field. Journal of Animal Ecology, 71, 524-531.

Singer, M.S. \& Stireman, J.O. (2005) The tri-trophic niche concept and adaptive radiation of phytophagous insects. Ecology Letters, $\mathbf{8}$, $1247-1255$.

Singer, M.S., Rodrigues, D., Stireman, J.O. III \& Carriere, Y. (2004) Roles of food quality and enemy-free space in host use by a generalist insect herbivore. Ecology, 85, 2747-2753.

Stamp, N.E. \& Bowers, M.D. (1996) Consequences for plantain chemistry and growth when herbivores are attacked by predators. Ecology, 77, 535-549.

Thompson, J.N. (2005) The Geographic Mosaic of Coevolution. University of Chicago Press, Chicago, Illinois.

Thompson, J.N. \& Pellmyr, O. (1991) Evolution of oviposition behavior and host preference in Lepidoptera. Annual Review of Entomology, 36, 65-89.

Tschanz, B., Schmid, E. \& Bacher, S. (2005) Host plant exposure determines larval vulnerability-do prey females know? Functional Ecology, 19, 391-395.

Valladares, G. \& Lawton, J.H. (1991) Host-plant selection in the holly leaf-miner-does mother know best? Journal of Animal Ecology, 60, $227-240$.

Vencl, F.V. \& Srygley, R.B. (2013) Enemy targeting, trade-offs, and the evolutionary assembly of a tortoise beetle defense arsenal. Evolutionary Ecology, 27, 237-252.

Vencl, F.V., Schultz, J.C., Mumma, R.C. \& Morton, T.C. (1999) The shield defense of a larval tortoise beetle. Journal of Chemical Ecology, 25, 549-566.

Vencl, F.V., Nogueira-de-Sá, F., Allen, B.J., Windsor, D.M. \& Futuyma, D.J. (2005) Dietary specialization influences the efficacy of larval tortoise beetle shield defenses. Oecologia , 145, 409-414.

Vencl, F.V., Trillo, P.A. \& Geeta, R. (2011) Functional interactions among tortoise beetle larval defenses reveal trait suites and escalation. Behavioral Ecology and Sociobiology, 65, 227-239.

Windsor, D.M. (1987) Natural history of a subsocial tortoise beetle, Acromis sparsa Boheman (Chrysomelidae: Cassidinae) in Panama. Psyche, 94, 127-150.

Yasuda, T. (1998) Effects of (E)- phytol of several lepidopteran species in prey locating behavior of generalist predatory stink bug Eocanthecona furcellata (Heteroptera: Pentatomidae). Entomological Science, 1, 159-164.

Zalucki, M.P., Clarke, A.R. \& Malcolm, S.B. (2002) Ecology and behavior of first instar larval Lepidoptera. Annual Review of Entomology, 47, 361-393.

Accepted 5 June 2013 